\title{
La existencia de boratos en las aguas de los manantiales q rios de los alrededores de la ciudad de Arequipa
}

\author{
POR LOS DOCTORES \\ MANUEL A. VELASQUEZ \\ Profesor de Quimica Médica en la Facultad de Medicina \\ EDMUNDO ESCOMEL \\ Y \\ ANGEL MALDONADO \\ De la Sección de Farmacia de la Facultad
}

\begin{abstract}
F L descubrimiento de boratos en las aguas de Jesús, realizado por dos de nosotros (Escomel y MALDONADO) en 19/2, y la existencia de borateras en la llamada laguna de «Salinas», señalada por VENEGAS en 1880 , nos indujeron a pensar que estos boratos pra cedían, probablemente, de esas borateras. Por otra parte, la naturaleza geológica de los terrenos y la diferencia de altitud entre la laguna de "Salinas y las fuentes termales vecinas a la ciudad de Arequipa confirmaban este origen, hipotesis que con el reciente hallazgo de boratos en los manantiales y ríos de Arequipa, ha encontrado plena comprobación.

A continuación, exponemos someramente el resultado de nuestras investigaciones acerca de la existencia de pequeñas cantidades de boratos en las aguas de los alrededores de Arequipa.
\end{abstract}

ACCION DE LOS RESIDUOS SALINOS DE LAS AGUAS DE AREQUIPA SOBRE LA CURCUMINA.

Técnica seguida: Se ha evaporado en capsula de platino hasta sequedad 100 c.c. del agua, motivo del analisis, se añadió al residuo de la evaporación, algunas gotas de $\mathrm{HCl}$ concentrado, después de agitación se añadio 2 c.c. de $\mathrm{H}^{2} \mathrm{O}$ destilada i se calento el residuo salino, hasta que se disolví en su mayor parte, se dejo enfriar, se 
sumergió entonces un papel de curcumina, después de humedecerlo totalmente se retiró i se desecó a suave calor; el papel de amarillo pálido que era, se tornó rojo característico; luego se dejo cater sobre éste nna gota de amoniaco concentrado, i en otka parte del papel una gota de solución acuosa de carbonato de sodi al 1/10: en ambos sitios el color rojo característico ha desaparecido tornándose en un color azul ultramar.

Siguiendo esta técnica, se ha tenido reacción positiva con las siguientes aguas:

Manantiales de Chiguata.

id. del Milagro, en Characato.

id. de Sabandia.

id. de Tingo.

id. de Sachaca (Baño de! Obispo).

id. de id. (Agua de Valencia).

id. de Yumina (tomada en las piletas de la ciudad de Arequipa).

Manantiales de la Media Luna, en.Tiabaya

id. de Sermanat.

id. de la Ollería (cerca del Cementerio General de Arequipa).

Manantiales de Hartley cerca de Paucarpata.

Manantiales del Puente de Fierro, Arequipa.

Agua del pozo de "Jesús».

id. del Negro, en Paucarpata.

id. de la Peña, en Socabaya.

id. del río Chili.

id. del río Sabandia.

id. del río Postrero

id. del tío Yura (*).

ACCiOn DE algunas eFÉRESCENCIAS SALINAS, SOBRE LA CURCUMINA Y FORMACION DE ETER METILBORICO CON DICHAS EFLORESCENCIAS.

10.- Se hizo la reacción del papel de curcumina, como se ha indicado al hablar de las aguas, con resultado positivo.

20. - A 3 gramos de muestra, en una cápsula de platino de $\mathbf{8 0}^{\mathbf{\prime}}$ c.c. de capacidad, se ar̃adie on 5 c.c. de acido sulfúrico concentra-

(*) Véase el mapa ádjuntu. lomitlo de faimondi, en el que estan ubicidos

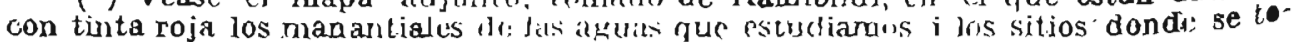
maron las muestras de las aguas de los ries de los alrodedores de Arequipa. 


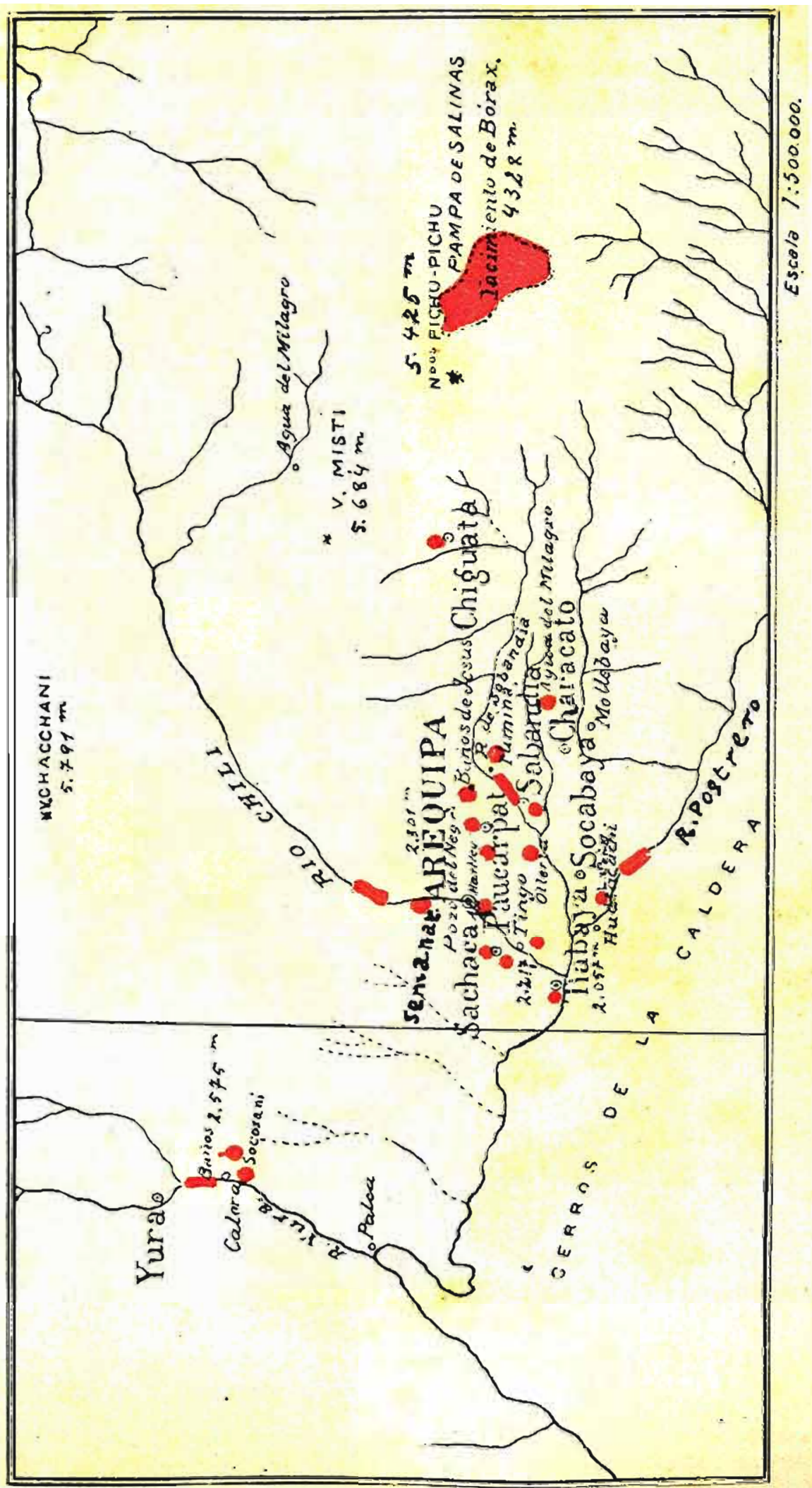


do, i se calentó agitando hasta la emision de vapores blancos, se siguió calentando, hasta la completa volatilización del acido sulfúrico, se dejó enfriar la cápsula i se añadieron unos 2 c.c. déácido sulfúrico, se calentó otra vez hasta la completa volatilización de uste, se continuó calentado a fín de destruir las materias orgánicas que pudieran existir. hasta que las sales contenidas en el crisol de platino se tornaron blancas, se dejó enfríar, se añadió entonces 3 c.c. de ácido sulfúrico i se calentó suavemente a fín de poder desprender con facilidad las sales adheridas a la cápsula. se agregó en seguida 5 c.c. de alcohol metílico; se agitb con preqaucín el contenido de la cápsula i se vertió en un tubo de ensayo, por medio de un embudo, cuidando de no mojar las paredes de la parte alta del tubo; el tubo de ensayo se calentó con precaución i cuando entró en ebullición se inflamaron los vapores desprendidos los que dieron la llama verde característica; inmediatamente que se apago, se siguió calentando; los vapores fueron recibidos en un papel de curcumina humedecido con ácido clorhídrico diluído ise deseco el papel que tom6 un color rojo, el cual por al amoniaco o por el carbonato de sodio viró al azul.

Este mismo método se ha seguido con el producto de la evaporación de las aguas de Jesús i del Negro, con resultado positivo.

Ademas el éter metilborico, formado con las eflorescencias de la Calera (Yura), se encausó a un refrigerante, obtení́ndose así un líquido, que al arder, lo hace con llama verde, i da igualmente la reacción positiva con el papel de curcumina.

Las reacciones han sido positivas, con las siguientes eflorescencias salinas:

Alrededores de los baños de Jesús.

id. del pozo Negro.

id. del manantial del agua del Milagro.

id. del id. del Puente de Fierro.

id. de las fuentes minerales de Yura i de los pastos de la Calera. (En la Calera denominan Salitre a estas sales).

Alrededores de las vertientes de Socosani, cerca de Yura. Principalmente, en las eflorescencias de los pastos cercanos a la casa de la finca Socosani.

CURCUMINA.

Antes de entrar al estudio i valor del método empleado en la busca del ácido bórico, por medio del papel de curcumina, recorhromos algo acerca de las propiedades generales de la curcumina, ie sus combinąciones i transformaciones. 
La curcumina es la materia colorante de la raíz de la Cúrcuma longa i de la C.viridiflora. A pesar de los innumerables trabqjos para determinar primero la fórmula global de la curcumina i des. pués su formula estructural no se ha llegado a una conclusion definitiva; para Ciamician i Silber sería $C^{21} \mathrm{H}^{20} \mathrm{O}^{3}$, para JaCKśon i MANKE $C^{14} \mathrm{H}^{\mathbf{1 4}} \mathrm{O}^{*}$, para DAUBE $\mathrm{C}^{10} \mathrm{H}^{10} \mathrm{O}^{2}$ i para IWANOF-G JEWSKI $\mathrm{C}^{4} \mathrm{H}^{4} \mathrm{O}^{4}$.

Richter, le atribuye las formulas indicadas por Ciamician i Silber, i la de Jackson i MANKe, debiendo advertirse que $\mathbf{R}_{\text {ICH- }}$ TER señala doce compuestos que responden a la formula $\mathrm{C}^{2} \mathrm{H}_{1}^{2 \boldsymbol{e}}$ i 28 cuerpos de la formula global $\mathrm{C}^{\mathbf{1 4}} \mathrm{H}^{14} \mathrm{O}^{4}$.

Para J ACKSON i MANKE la fórmula estructural sería la siguiente

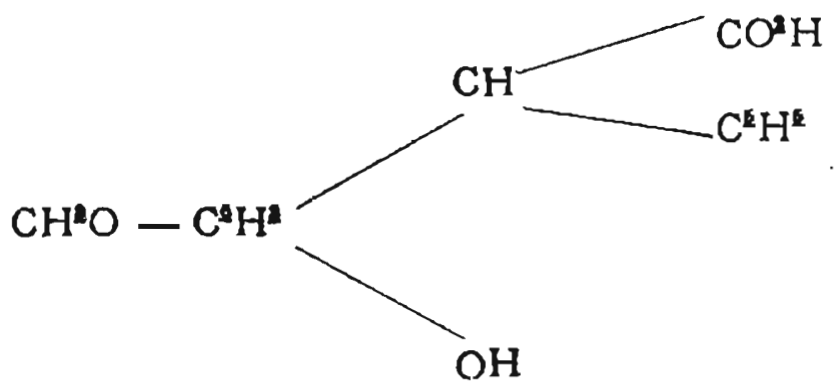

Pero esta formula no puede tomarse como definitiva.

La curcumina se presenta en cristales prismáticos, rombidales, amarillentos, brillantes, de sabor acre; el punto de fusión, según Ciamician i Silber, es $183^{\circ}$ i según JaCkson de 1780; 'son insolubles en el agua, en el eter de petroleo i en el sulfuro de çarbono; muy poco soluble en el benzol 1/2000; solubles en el etanıl, etano-oxi-etano, metanol, cloroformo, sobre todo en caliente; luble en el ácido acético. Las soluciones de curcumina presectan una bella fluorescencia verdosa.

Los álcalis cáusticos y los carbonatos, en solucion acuesa, disuelven la curcumina con coloración pardo rojiza, por lo que, algunas veces, se emplea el papel de cúrcuma para reconocimient de los álcalis libres o carbonatados. Los ácidos minerales diluidos devuelven a la curcumina el color amarillento primitivo que tenía antes del empleo de los álcalis y carbonatos alcalinos.

Los ácidos minerales concentrados le dán una coloración je carmesí.

Precipita con las sales de calcio i de bario, con coloración $\mathbf{p}^{2^{Y-}}$ do rojiza.

Con las sales plúmbicas, dá un precipitado de color roj de fuegon. 
Los oxidantes transforman la curcumina, según la acción del ágente oxidante empleado, en ácido carbónico i ácido acético, en acido oxálico, o en vainillina.

El ácido crómico, la transforma en ácido tereftálico.

Las sustancias reductoras, como la amalgama de zinc, la transforman en dehydrocurcumina $\left(\mathrm{C}^{14} \mathrm{H}^{10} \mathrm{O}^{4}\right)$.

La potasa cáustica fundida, da lugar a la formación de ácido protocatéquico.

Tratandola por solución acuosa de potasa, a la ebullición, se obtiene ácido vanillico ì ferúlico.

El anhîdrico acético, la convierte en diacetil-curcumina.

Haciendo actuar una solución pirídica de cloruro de benzoilo, se obtiene tribenzoil-curcumina.

El ácido acético, con polvos de zinc, después de larga ebullición, la transforma en anhidrido de la hidro-curcumina.

El bromo, actuando sobre la solución acética, forma hexabromocurcumina.

Ahora bien, si observamos en conjunto los cuerpos resultantes de las combinaciones de la curcumina o de las transformaciones de ésta, vemos que unos son incoloros, otros amarillentos, otros parduzcos, otros rojo carmesí, etc: pero, ninguno de los menclonados es de color azul o verde azulado, pues hasta hoy solo se conoce una sustancia derivada de la curcumina que se disuelve en los álcalis con coloración azul, i este derivado parece que sólo es producido por la acción del ácido bórico sobre la curcumina, o de los boratos acidulados por el acido clorhídrico.

FUndamento I VALOR DE LA REACCION DE IA CURCUMINA CON EL ACIDO BORICO.

La reacción con el papel de cúrcuma, para el reconocimiento del ácido borico es de uso muy antiguo i esta adoptado por todos los laboratorios de química. Esta reacción fué señalada por VoGel en 1815.

CAssal, con justa razón, ha reemplazado el polvo de cúrcuma, con la curcumina, obteniéndose con esta reacciones más puras.

WADE recomienda transformar el ácido bórico en éter metilbórico, i recibir los vapores de este éter sobre el papel de cúrcuma o de curcumina. Esta forma de proceder, facilita la comprobación del ácido bórico, por estar reunidos dos procedimientos en uno solo: por un lado se observa la llama verde del éter metilbó- 
rico, i por otra, se obtiene la reacción con la curcumina, actuando únicamente sobre esta el éter metilbórico formado.

El ácido bórico, o los boratos en solución acuosa, acidificados por el ácido clorhídrico, actúan sobre la curcumina, dando lugar a la formación de una sustancia de color rosa a la que SCHLUMBERGER en 1866 llamó Rosocyanina. La rosocyanina ha sido obténida al estado cristalino por DAUBE.

IWANOF-GAJEWSKI la ha obtenido en estado puro, por medi del extracto alcohólico de cúrcuma, ácido bórico i ácido sulfúrico en caliente.

La rosocyanina, se presenta bajo la forma de agujas de coler rojo oscuro, con reflejos verdes; es insoluble en el agua, éter sulfúrico i benzol; es soluble en el alcohol al que dá una coloración resada o rojiza "que cambia rápidament e»; la rosocyanina se disuelve y se combina con los álcalis cáusticos, con un color azul ultramar pasajero, que por la acción "de un ácido toma otra vez el color resa o rojizo.

La rosocyanina es un cuer po muy alterable; por la acción prelongada del etanol hirviendo se transforma en pseudo-curcumina.

Si al hacer actuar sobre la curcumina la solución de un borate, acidificado por el ácido clorhídrico, se añaden algunas gotas de solución acuosa de ácido oxálico, el color rojo del papel de curcumina se aviva mucho, i siempre se disuelve en los álcalis con una coloración azul mas o menos intensa.

"La solución alcalina (de rosocyanina) se vuelve grís por expasíción al aire i dá precipitado azul con agua de cal o de baritas.

Conviene al buscar el ácido bórico, por la: formación de ros cyanina, aprovechando el papel de curcumina, desecar el papel al calor suave i dejar caer sobre él la gota de amoniaco o de carbonato de soda inmediatamente después de su desecación; pues si se calienta demasiado o se añade el amoniaco o el carbonato de soda, días después de haber desecado el papel, la coloracion azul que debía observarse no se observará muy clara o no se présentará.

Aprovechando de que el ácido bórico libre o los boratos acidificados por el ácido clorhídrico, al actuar sobre el papel o las soluciones de curcumina, forman rosocyanina de color rosa, i que esta se disuelve o se combina con los álcal is cáusticos o carbonatades, disolviéndose en ellos con color azul ultramar pasajero, se dib como reacción característica del ácido bórico o de los boratos, el color rosa o pardo rojizo de la rosocyanina formada i el color azul de las soluciones de esta con los álcal is cáusticos o carbonatados. 
La mayor parte de los tratados de Química analítica, dan como reacción característica del ácido bórico, la de la curcumina i muy raros autores manifiestan reserva o no la dán como específica.

Así para BotTGer resta reacción no es especialmente caracteristica; puesto que otros ácidos dan igual reacción» i Agell Agell manifiestan que nesta reacción muy sencilla i cómoda, debe tomarse con precaución, porque la solución clorhídrica de zircono, titano, tántalo, niobío ì molidbeno empardecen igualmente el papel de cúrcuma,pero no dicen si esta coloración parduzca se hace azulada o verdosa por los álcalis cáusticos o carbonatados, que es lo verdaderamente característico en la reacción con el ácido bórico

Apoyándonos en las opiniones de Bortrer i Agell Agell, deberíamos mantener cierta reserva acerca del valor de la coloración pardo rojiza del papel curcumina, que en los exámenes de las aguas citadas hemos obtenido; pero como esta coloración rojiza a) disolverse en el amoniaco o en el carbonato de sodio, lo hace con color azul ultramar, todo hace creer que estamos en presencia de la rosocyanina formada por el ácido bórico contenido en las aguas que estudiamos.

\section{Observaciones}

1a.-El papel de curcumina se ha preparado disolviendo en etanol de $95^{\circ}$ curcumina, al 1/8.000, de la casa Poulenc.

2a.-Conviene hacer presente, como se vé en el mapa adjunto, la existencia de Boronatrocalcita, en Salinas, explotada en la actualidad con el nombre de Borato de Salinas.

3a.-El ácido b6rico no se encuentra libre, sino combinado, tanto en las aguas, como en las eflorescencias.

\section{Conclusiones}

1a.-La pequeña cantidad de agua disponible, para los análisis de las aguas de los manantiales i rios de la ciudad de' Arequipa, no nos han permitido hacer con la mayor parte de ellas sino la reacción con el papel de curcumina, la que ha sido en todas las aguas consignadas, francamente positiva, debiendo concluirse, que en todas estas aguas hay boratos en disolucion, aunque en muy pequeña cantidad

En el producto de la evaporación de las aguas de Jesús i del Negro, hemos constatado ademas la existencia de boratos, que hemos transformado en eter. mitilbórico que ha ardido con llama verde. 
2 a.-Del estudio practicado sobre las eflorescencias salinas mencionadas, en donde se ha obtenido la reacción de la curcumina positiva, i con las que se ha formado eter metilbórico (llama verde), nos autoriza a decir que en las mencionadas eflorescencias hay boratos, los que existen en pequeña cantidad.

NOTA

Debemos llamar la atención sobre el hecho de que las eflerescencias salinas estudiadas proceden de las inmediacianies de algunas de las fuentes cuyas aguas acusan reaccion positiva co el papel de curcumina, apoyando esto que la reacción obtenla con el papel de curcumina en las aguas analizadas es debida boratos. Además, que en dos de estas aguas hemos constatado sobre el resíduo de la evaporación. por formación de eter metilbórico, la presencia de boratos.

\section{Bibliografia}

Roche Raoul.-Formulaire Général des Reactions et Réactifs Chimiques et Microscopiques.-París.

Fluckiger F. A. ET Hanbury D.-Histoire des Bragues $D^{\prime}$ origine Végétale.-París 1878.

Schmidt E.-Tratado de Quimica Farmacéutica.-Tomo II. -Barcelona.

Schmidt E.-Tratado de Química Farmacéutica.-Tomo I. Barcelona.

Thомas V. - Les Plantes tinctoriales et leurs principes colorants.-París.

Richter M. M. von.-Lexikon der Kohlenstoff Verbinduxgen.-Dritte auflag.-III Teil.-Loipzig 1911.

Peckolt T. i Peckolt G.-Historia das plantas Medicinas e Uters do Brazil.-Fascículo 5.-Río de Janerro 1898.

Allen s Commercial.-Organic Analysis.-Volumen, V. London 1911.

BotTGER.-The principles of Quantitative Analysis.-Leipzis 1906.

Agell i Agell. - Tratadi de Análisis Quimico.-1910.-páb. 299. 